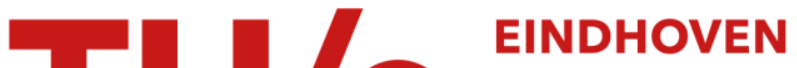 UNIVERSITY OF TECHNOLOGY
}

\section{Shape transition of coherent three-dimensional (In, Ga)As islands on $\mathrm{GaAs}(100)$}

\section{Citation for published version (APA):}

Ma, W., Nötzel, R., Schönherr, H-P., \& Ploog, K. (2001). Shape transition of coherent three-dimensional (In, Ga)As islands on GaAs(100). Applied Physics Letters, 79(25), 4219-4221. https://doi.org/10.1063/1.1428107

DOI:

$10.1063 / 1.1428107$

Document status and date:

Published: 01/01/2001

\section{Document Version:}

Publisher's PDF, also known as Version of Record (includes final page, issue and volume numbers)

\section{Please check the document version of this publication:}

- A submitted manuscript is the version of the article upon submission and before peer-review. There can be important differences between the submitted version and the official published version of record. People interested in the research are advised to contact the author for the final version of the publication, or visit the $\mathrm{DOI}$ to the publisher's website.

- The final author version and the galley proof are versions of the publication after peer review.

- The final published version features the final layout of the paper including the volume, issue and page numbers.

Link to publication

\section{General rights}

Copyright and moral rights for the publications made accessible in the public portal are retained by the authors and/or other copyright owners and it is a condition of accessing publications that users recognise and abide by the legal requirements associated with these rights.

- Users may download and print one copy of any publication from the public portal for the purpose of private study or research.

- You may not further distribute the material or use it for any profit-making activity or commercial gain

- You may freely distribute the URL identifying the publication in the public portal.

If the publication is distributed under the terms of Article 25fa of the Dutch Copyright Act, indicated by the "Taverne" license above, please follow below link for the End User Agreement:

www.tue.nl/taverne

Take down policy

If you believe that this document breaches copyright please contact us at:

openaccess@tue.nl

providing details and we will investigate your claim. 


\title{
Shape transition of coherent three-dimensional (In,Ga)As islands on $\operatorname{GaAs}(100)$
}

\author{
Wenquan Ma, ${ }^{\text {a) }}$ Richard Nötzel, ${ }^{\text {b) }}$ Hans-Peter Schönherr, and Klaus H. Ploog \\ Paul-Drude-Institut für Festkörperelektronik, Hausvogteiplatz, 5-7, D-10117 Berlin, Germany
}

(Received 13 August 2001; accepted for publication 26 October 2001)

\begin{abstract}
The shape transition of coherent three-dimensional (3D) islands is observed experimentally in the (In,Ga)As/GaAs(100) material system. In the molecular-beam epitaxy of a 1.8-nm-thick $\mathrm{In}_{0.35} \mathrm{Ga}_{0.65} \mathrm{As}$ single layer, we find that the shape of the coherent $3 \mathrm{D}$ islands transforms from round to elongated when increasing the growth temperature. A quantitative agreement of our experimental data with the theoretical work of Tersoff and Tromp is achieved. (C) 2001 American Institute of Physics. [DOI: 10.1063/1.1428107]
\end{abstract}

For Stranski-Krastanov systems, uniform twodimensional (2D) layers can relax by undergoing a morphological change of the surface profile without generating dislocations. ${ }^{1,2}$ This strain-induced morphological instability results in the formation of coherent three-dimensional (3D) islands whose shape is usually isotropic or elongated. There has been great interest in the shape of these islands for the direct synthesis of quantum dot and quantum wire structures which have unique applications for novel optoelectronic devices. We have recently demonstrated formation of a quantum wire structure based on elongated islands in the (In,Ga)As/GaAs(100) material system. ${ }^{3}$ On the other hand, Tersoff and Tromp ${ }^{4}$ predicted that a shape transition should occur for 3D islands if the growth of the island height is kinetically limited. Subsequent theoretical work has shown that such a shape transition is a common feature for both $3 \mathrm{D}^{5}$ and $2 \mathrm{D}^{6,7}$ islands, which was confirmed for $\mathrm{CoSi}_{2}$ on $\mathrm{Si}(100) .{ }^{8}$ However, to the best of our knowledge, the shape transition has so far not been reported experimentally in III-V semiconductor systems. Moreover, experimental routes to reproducibly realize the shape transition are technologically important.

In this letter, we demonstrate the shape transition of $3 \mathrm{D}$ (In, Ga)As islands grown on $\mathrm{GaAs}(100)$ by molecular-beam epitaxy. For 1.8-nm-thick (In,Ga)As single layers, we show that the formation of $3 \mathrm{D}$ islands is a kinetically limited process. The shape transition is realized by changing the growth temperature. A good agreement is obtained between our experimental data and the theoretical work of Tersoff and Tromp. ${ }^{4}$

Three 1.8-nm-thick (In,Ga)As single-layer samples were grown on GaAs (100) substrates with miscut smaller than $0.05^{\circ}$ at temperatures of 540,475 , and $430{ }^{\circ} \mathrm{C}$. After the native oxide was desorbed from the GaAs substrate surface at $580{ }^{\circ} \mathrm{C}$, a 110 -nm-thick GaAs buffer layer was grown before the substrate was cooled down to the temperature for (In,Ga)As deposition. The In mole fraction was calibrated by $\mathrm{X}$-ray diffraction of an (In,Ga)As/GaAs superlattice sample

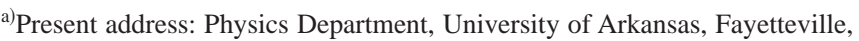
AR 72701; electronic mail: wqma@uark.edu

${ }^{b)}$ Present address: COBRA Inter-University Research Institute, Eindhoven University of Technology, 5600 MB Eindhoven, The Netherlands.
}

grown continuously at $540^{\circ} \mathrm{C}$. The In mole fraction is 0.35 and the $\mathrm{As}_{4}$ to $\mathrm{Ga}$ flux ratio is about 5. The growth rate of GaAs and $\mathrm{In}_{0.35} \mathrm{Ga}_{0.65} \mathrm{As}$ is 0.235 and $0.3615 \mu \mathrm{m} / \mathrm{h}$, respectively. Characterization of the surface morphology was performed by atomic force microscopy (AFM) in contact mode in air with a $75 \mu \mathrm{m}$ scanner.

Figures 1(a), 1(b), and 1(c) depict the AFM top views of the $\operatorname{In}_{0.35} \mathrm{Ga}_{0.65} \mathrm{As}$ single-layer samples grown at temperatures of 540,475 , and $430{ }^{\circ} \mathrm{C}$, respectively, revealing the formation of $3 \mathrm{D}$ islands. At relatively low growth temperatures [Figs. 1(b) and 1(c)], round-shaped islands are observed, whose size increases with increasing the growth temperature. The average island diameters are about $28 \mathrm{~nm}$ [Fig. 1(b)] and $18 \mathrm{~nm}$ [Fig. 1(c)], respectively. In contrast, at $540{ }^{\circ} \mathrm{C}$ [Fig. 1(a)], the islands are elongated. For most islands, the length to width ratio is about 6 with the island width of about $40 \mathrm{~nm}$. This demonstrates that, for fixed In mole fraction and layer thickness, the size and, most importantly, the shape of these dislocation-free islands (see Ref. 3) are varied by solely changing the growth temperature. Since the growth temperature directly governs the surface diffusion length, this is a first indication that the formation of these coherent $\operatorname{In}_{0.35} \mathrm{Ga}_{0.65} \mathrm{As}$ islands is a kinetically limited process. ${ }^{9}$ To compare, we grew a 1.8 -nm-thick (In,Ga)As single-layer sample with larger In mole fraction of 0.45 at $540{ }^{\circ} \mathrm{C}$. The AFM image [Fig. 3(a)] of this sample reveals almost round-shaped islands. Thus, for a certain growth tem- (a)

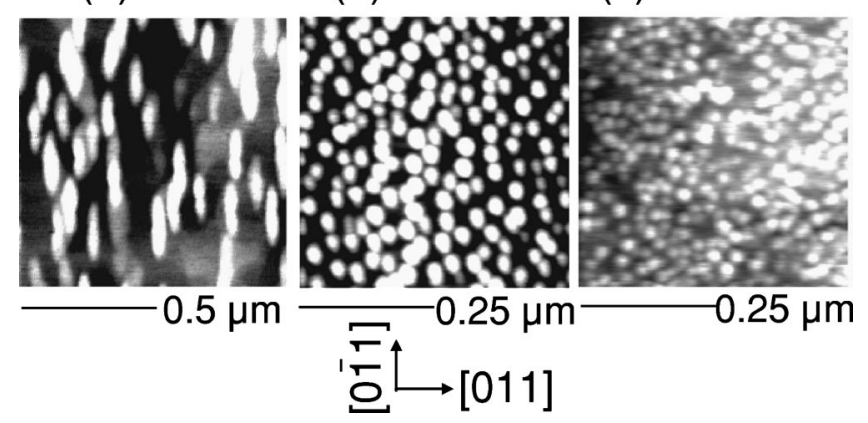

FIG. 1. AFM top views of the 1.8-nm-thick $\operatorname{In}_{0.35} \mathrm{Ga}_{0.65} \mathrm{As}$ single-layer samples grown at 540 (a), 475 (b), and $430{ }^{\circ} \mathrm{C}$ (c) on $\operatorname{GaAs}(100)$. The black-to-white height contrast is $3 \mathrm{~nm}$ for all images. 


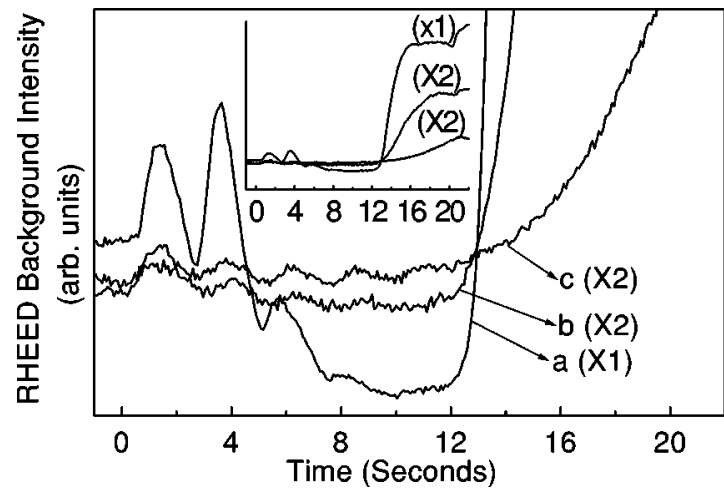

FIG. 2. RHEED intensity during the growth of $\operatorname{In}_{0.35} \mathrm{Ga}_{0.65} \mathrm{As}$ on $\mathrm{GaAs}(100)$ at substrate temperatures of 540 (a), 475 (b), and $430{ }^{\circ} \mathrm{C}$. (c). The observation is along the [011] azimuth from a window set at the background. The inset shows the same curves with low magnification.

perature, the shape of the islands is also determined by the In mole fraction with larger In mole fraction (strain) favoring isotropic islands.

The evolution of the (In,Ga)As layers for the three samples was monitored in situ by reflection high-energy electron diffraction (RHEED) with the incident electron beam along [011]. Figures 2(a), 2(b), and 2(c) depict the RHEED intensity taken from a window set in the background during deposition of the (In, Ga)As layers grown at 540,475 , and $430{ }^{\circ} \mathrm{C}$, respectively, i.e., corresponding to the samples with the surface morphologies shown in Figs. 1(a), 1(b), and 1(c). The RHEED intensity oscillations in the initial deposition stage reveal layer-by-layer growth until about four (In,Ga)As monolayers. Afterwards, the RHEED intensity oscillations become suppressed due to the onset of $3 \mathrm{D}$ island formation confirming the Stranski-Krastanov growth mode. The intensity recorded from the background is dominated by diffuse scattering. ${ }^{10}$ Therefore, when the growth mode transforms from $2 \mathrm{D}$ to $3 \mathrm{D}$, the background intensity continuously increases and finally stabilizes. The different background intensities for the three samples in the final growth stage shown in the inset of Fig. 2 clearly indicate the different surface morphology and we observe stronger diffuse scattering for larger island size at higher growth temperature. The period of the RHEED intensity oscillations in the initial growth stage confirms that In desorption is negligible for growth temperatures below $540{ }^{\circ} \mathrm{C}$.

It is surprising that we observe $2 \mathrm{D}$ growth only for the first four monolayers of the 1.8-nm-thick (In,Ga)As layer with In mole fraction of only 0.35 . However, also this layerby-layer growth is a kinetically limited process. ${ }^{11}$ For constant lattice mismatch, the transition thickness from $2 \mathrm{D}$ to coherent 3D island formation increases with decreasing growth temperature, i.e., decreasing surface diffusion length. Correspondingly, the growth of a 1.8-nm-thick (In,Ga)As single layer with the same In composition of 0.35 grown at $330^{\circ} \mathrm{C}$ is found to be 2D-like, as shown in Fig. 3(b).

In the following we describe the shape transition of the $\mathrm{In}_{0.35} \mathrm{Ga}_{0.65} \mathrm{As}$ islands within the frame of the theoretical work of Tersoff and Tromp. ${ }^{4}$ The island energy per unit volume can be written as

$$
\frac{E}{V}=2 \Gamma\left(\frac{1}{s}+\frac{1}{t}\right)-2 c h\left[\frac{1}{s} \ln \left(\frac{s}{\phi h}\right)+\frac{1}{t} \ln \left(\frac{t}{\phi h}\right)\right],
$$

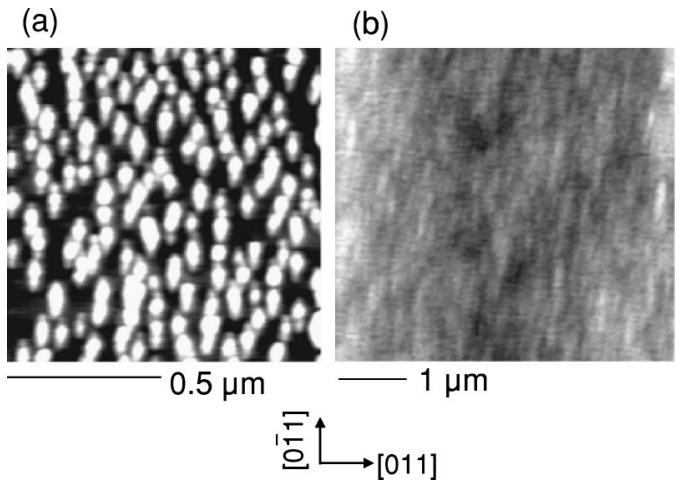

FIG. 3. AFM top views of the 1.8-nm-thick (In,Ga)As single-layer samples with In mole fraction of 0.45 grown at $540{ }^{\circ} \mathrm{C}$ (a), and with In mole fraction of 0.35 grown at $330^{\circ} \mathrm{C}$ (b). The black-to-white height contrast for (a) and (b) is 3 and $2 \mathrm{~nm}$, respectively.

where $E$ denotes the island energy, $s, t$, and $h$ the width, length, and height of the island, respectively, and $V=h s t$ the island volume. $\theta$ is the contact angle; $\Gamma=\gamma_{e} \csc \theta-\gamma_{s} \cot \theta$ with $\gamma_{e}$ and $\gamma_{s}$ the surface free energy per unit area of the edge facet of the island and of the substrate, respectively. $c$ $=\sigma_{b}^{2}(1-\nu) / 2 \pi \mu$, where $\nu$ and $\mu$ are the Poisson ratio and the shear modulus of the substrate. $\phi=e^{-3 / 2} \cot \theta$, and $\sigma_{b}$ is the bulk stress of the island. Corresponding to the thermodynamic limit, ${ }^{12}$ minimization of the energy per unit volume $E / V$ with respect to the island width $s$ and length $t$ by optimizing the volume of the island results in $s=t=a_{0}$ $=e \phi h e^{\Gamma / c h}$, i.e., square-shaped islands. In contrast, for a kinetically limited process with constant island height $h$ which we show to apply for our experimental situation, minimization of the energy per unit volume $E / V$ with respect to the island shape for fixed island volume gives $s=t$, provided the area of the island is smaller than $e a_{0} \times e a_{0}$. For larger area, the island becomes elongated. This corresponds to the case where the adatom diffusion length is small enough that migration between islands can be neglected and deposited material only attaches to the nearest island. The island will then grow without bounds and, for a certain island volume, the island shape is determined by Eq. (1). Hence, when the island becomes large enough, the optimal trade-off between surface energy and strain energy causes transformation into elongated shape. The solid line in Fig. 4 shows the width and length of the island as a function of its area according to Eq. (1). The bifurcation point in Fig. 4 corresponds to the island area of $\left(e a_{0}\right)^{2}$ beyond which the island shape becomes elongated.

Good agreement between the theory and our experimental data is obtained for $a_{0}=280 \AA$. For the calculation, the island height $h$ of $1.8 \mathrm{~nm}$ and the contact angle $\theta$ of $9.3^{\circ}$, are determined from AFM line scans. The appropriate reference for $\gamma_{s}$ for the Stranski-Krastanov growth mode is that of the wetting layer. Thus, we use $\gamma_{e}=57 \mathrm{meV} / \AA^{2}$ and $\gamma_{s}$ $=57 \mathrm{meV} / \AA^{2}$ (see the following). The elastic moduli of $\mathrm{In}_{0.35} \mathrm{Ga}_{0.65} \mathrm{As}$ of $C_{11}=10.592 \times 10^{11} \mathrm{dyn} / \mathrm{cm}^{2}$ and $C_{12}$ $=5.042 \times 10^{11} \mathrm{dyn} / \mathrm{cm}^{2}$ are obtained by interpolating between the data for GaAs and $\operatorname{InAs}^{13}$ according to the In mole fraction. As a result, we get $\Gamma=4.63 \mathrm{meV} / \AA^{2}$ and $a_{0}$ $=281.4 \AA$. The closed circles in Fig. 4 correspond to the experimental data determined from Fig. 1. Larger islands could not be obtained for the present In mole fraction and 


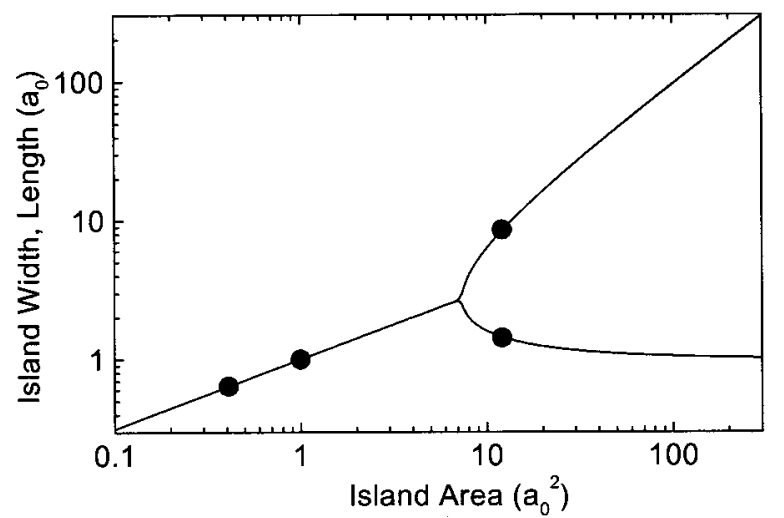

FIG. 4. The solid line shows the width and length of the island as a function of the area calculated numerically according to Eq. (1). The closed circles are the experimental data points corresponding to Figs. 1(a)-1(c). $a_{0}$ $=280 \AA$.

(In, Ga)As layer thickness due to In desorption upon further increase of the growth temperature.

Several important features should be considered when comparing the model with our experimental findings. First, the island height $h$ is to be kept constant. In our approach, we realize the shape transition by deposition of a constant number of monolayers of material at different growth temperatures. In principle, coherent 3D strained islands can lower their strain energy by increasing their height. However, as discussed previously, if the increase in height is kinetically limited, the island grows only laterally, i.e., the island height grows much slower than the width and shape transition occurs. Indeed, from the AFM images [Figs. 1(a)-1(c)], the average height of the islands corresponding to the samples grown at different temperatures is relatively constant. Even at $540{ }^{\circ} \mathrm{C}$, which is closer to thermal equilibrium, the island height only slightly increases, which is the key point for understanding the observed shape transition. Second, the surface free energy of (In,Ga)As for arbitrary In composition is not well documented in the literature. Therefore, the values for the calculation are estimated from a linear interpolation between the data for $\mathrm{GaAs}(100)$ and $\operatorname{InAs}(100)$ which are, respectively, 65 and $44 \mathrm{meV} / \AA^{2}$ according to Refs. 14 and 15. Finally, the values of $\gamma_{e}$ and $\gamma_{s}$ are assumed to be equal.
This may be justified by the small contact angle of only about $9.3^{\circ}$ by considering the Wulff plot of the surface free energy with respect to the surface orientation. ${ }^{16}$

In summary, we have experimentally demonstrated the shape transition of coherent 3D islands in the (In,Ga)As/ $\operatorname{GaAs}(100)$ material system. A series of 1.8-nm-thick (In, Ga)As single layers were grown on GaAs(100) at different temperatures. The surface morphology of the samples was characterized by atomic force microscopy and reflection high-energy electron diffraction. The shape of the coherent 3D islands transforms from round to elongated when increasing the growth temperature. This shape transition is understood by the theoretical work of Tersoff and Tromp. A quantitative agreement is obtained between the theory and our experimental results.

Part of this work was supported by the Bundesministerium für Bildung und Forschung, and the NEDO NTDP-98 project.

${ }^{1}$ D. J. Eaglesham and M. Cerullo, Phys. Rev. Lett. 64, 1943 (1990).

${ }^{2}$ S. Guha, A. Madhukar, and K. C. Rajkumar, Appl. Phys. Lett. 57, 2110 (1990).

${ }^{3}$ W. Q. Ma, R. Nötzel, A. Trampert, M. Ramsteiner, H. J. Zhu, H.-P. Schönherr, and K. H. Ploog, Appl. Phys. Lett. 78, 1297 (2001).

${ }^{4}$ J. Tersoff and R. M. Tromp, Phys. Rev. Lett. 70, 2782 (1993).

${ }^{5}$ C. D. Rudin and B. J. Spencer, J. Appl. Phys. 86, 5530 (1999).

${ }^{6}$ I. Daruka, J. Tersoff, and A.-L. Barabási, Phys. Rev. Lett. 82, 2753 (1999).

${ }^{7}$ A. Li, F. Liu, and M. G. Lagally, Phys. Rev. Lett. 85, 1922 (2000).

${ }^{8}$ S. H. Brongersma, M. R. Castell, D. D. Perovic, and M. Zinke-Allmang, Phys. Rev. Lett. 80, 3795 (1998).

${ }^{9}$ G. S. Solomon, J. A. Trezza, and J. S. Harris, Jr., Appl. Phys. Lett. 66, 991 (1995).

${ }^{10}$ P. J. Dobson, B. A. Joyce, J. H. Neave, and J. Zhang, in Surface and Interface Characterization by Electron Optical Methods, edited by A. Howie and U. Valdrè (Plenum, New York, 1988), p. 185.

${ }^{11}$ C. W. Snyder, J. F. Mansfield, and B. G. Orr, Phys. Rev. B 46, 9551 (1992).

${ }^{12}$ J. Tersoff, in Low Dimensional Structures Prepared by Epitaxial Growth or Regrowth on Patterned Substrates, edited by K. Eberl, P. M. Petroff, and P. Demeester (Kluwer Academic, Dordrecht, 1995), p. 13.

${ }^{13}$ Landolt-Börnstein, edited by O. Madelung (Springer, Berlin, 1982), Vol. $17 \mathrm{a}$.

${ }^{14}$ N. Moll, M. Scheffler, and E. Pehlke, Phys. Rev. B 58, 4566 (1998).

${ }^{15}$ N. Moll, A. Kley, E. Pehlke, and M. Scheffler, Phys. Rev. B 54, 8844 (1996)

${ }^{16}$ A. Zangwill, in Epitaxy: Physics at Surfaces (Cambridge University Press, New York, 1988). 